\title{
CORRESPONDENCE
}

\section{Data on dioxin}

\section{SIR - In discussing the metabolism of} chlorinated dioxins, Alastair Hay ${ }^{1}$ reviews the epidemiological evidence for an association between soft tissue sarcomas and phenoxy herbicides.

In fact the evidence in favour of an association is much stronger than he suggests. He fails to mention that in addition to the findings of the surveys of two different groups of Swedish agricultural and forestry workers exposed to phenoxy acids and chlorophenols 2,3 , studies of industrial workers exposed to these substances during manufacture in the United States have also been published. A review of four such studies ${ }^{4}$ showed that 3 of 105 deaths in the workers under observation had been due to soft tissue sarcomas. This compares with 0.07 per cent of deaths in the total population of US males aged 20-84. Since the publication of this review a fourth (non-fatal) case of soft tissue sarcoma has been reported in one of these groups of men 5 . A fifth case has been described in an employee of one of the American firms but it is not clear whether he was under observation as part of one of the published cohorts ${ }^{6}$.

The Finnish study quoted by Alastair Hay has not followed a sufficient number of men for a long enough period to furnish other than weak negative evidence. The study might easily have missed an increased relative risk of five.

The epidemiological data cannot at present distinguish between a risk due to 2,4,5-T itself (or to related herbicides) and one which is due to contaminants of these compounds.

\section{MRC Environmental \\ Epidemiology Unit, \\ University of Southampton, UK}

E.D. ACHESON

1. Hay, A. Nature 294, 514 (1981)

2. Hardell, L. \& Sandstrom, A. Br. J. Cancer 39, 711 (1979).

3. Eriksson, M. et al. Br. J. ind. Med, 38, 27 (1981).

4. Honchar, P.A. \& Halperin, W.E. Lancet i, $268(1981)$.

5. Cook, R.R. Lancet i, 618 (1981).

6. Moses, M. \& Selikoff, I. J. Lancet i, 1370 (1981).

\section{Beat the clock}

SIR - The anonymity of journals' referees has been much discussed. A common nuisance is the tardy referee who sits on papers sometimes for months, and about whom authors can do little. I believe these could be dealt with effectively if the anonymity of referees were maintained for say a month from dispatch to them of the manuscript. After that the editor would automatically pass on the identity of the offender to the authors who could, and usually would, then take up the cudgels directly on their own behalf.

I am sure this simple measure would effect a speedy acceleration of the turnover time of papers in editorial offices. Many of us who are sometimes authors, sometimes referees, would, I am sure, accept this constraint on our latter function in the interests of our former.

P. C. WILKINSON

Department of Bacteriology and Immunology,

University of Glasgow, $U K$

\section{Niche work}

SIR - Concerning H.G. Pickles' imagined

"very small niche indeed" (Pharmacology Issues, Nature 1 October 1981, p.355) for Journal of Ethnopharmacology compared with Journal of Cardiovascular Pharmacology I propose that more people can certainly be directly involved and interested in what plants they can eat or apply therapeutically or in any other useful way (because anyone may pluck, cultivate or look for plants) than can be directly involved in cardiovascular drugs (because they are not readily available).

All the best to cardiovascular pharmacologists, but please watch out for the relegation to niches. (To be honest, I did think I was writing esoterica when I submitted my first article to Journal of Ethnopharmacology . . . but there must be a lot of people out there in a lot of very small niches, because I received 48 reprint requests immediately following publication, and they are still dribbling in.)

HOWARD H. HIRSCHHORN

Arlesheim, Switzerland

\section{Morphic field sports}

SIR - The rather intemperate reaction of Nature to Sheldrake's hypotheses (24 September 1981, p.245), against which Josephson has protested (Nature 15 October 1981, p.594), is in part the result of Sheldrake's own choice of Bergsonian - or Paracelsan - explanations for the effect he postulates, and in part the result of noncommunication between biology and physics.

Had Sheldrake said that the quantum interconnectedness might extend to macrosystems, including biological systems, I do not think that Nature would have felt that its virginity was in peril. A model of interconnectedness does in fact flow from Bohm's idea of explication. The experimental agenda is to see how far beyond the subatomic level this patterning extends. If particles correspond to the asteroids and space-ships of a video game, appearing to behave as objects subject to cause-effect, but being in fact virtual displays built up from pulses which bear no translational resemblance to the "display", Darwinian evolution might well be (some would say, "must be") a video game of the same order, appearing to follow simple selection-adaptation principies, as the gamepieces appear to collide, explode and so on but in fact determined by information from an implicate substrate.

The relevance of interconnectedness to middle-order systems looks like a prime candidate for confirmatory research. If it were confirmed, Sheldrake would be both right in principle and wrong in his postulated mechanism of "morphic fields": viewed in this way, his suggestion is far from absurd.

One awaits with interest Nature's reaction to the first book which points out that Bohm's model also blows up the convention of Helmholtzian mind. That suggestion might prove even more alarming than a physicsbased neovitalism.

UCLA Neuropsychiatric Institute, California, USA

\section{Dead-end theory}

SIR - In a recent letter Darnbrough, Goddard and Stevely (Nature 2 December 1981, p.302) have argued in support of Creationism. They claim that given belief in a God who reveals Himself in the structure of nature they "expect to find evidence consistent with His revelation of Himself". In their view "the fact that all things exist, and show evidence of design and purpose $\mathrm{e}^{\mathrm{x}}$ is the only form of empirical evidence providing support for Creationism.

In their arguments, your correspondents have forgotten that evidence which is merely consistent with a theory does not necessarily support that theory. An illustration of this is that all possible evidence is consistent with the hypothesis that one minute ago a God created everything in the Universe, including our memories. Clearly, for an observation to be consistent with a theory is only a necessary but not sufficient condition for it to provide that theory with evidential support.

A fundamental problem with creation theories is that because the mechanisms proposed are supernatural, the theories fail to provide an explanation of natural phenomena which can be further investigated, developed and understood. In fact, unlike present evolutionary theory, all theories which invoke a supernatural creator are scientific dead ends, failing to lead to new knowledge.

This difference between creation theory and modern evolutionary theory can be illustrated by considering how each handles anomalous evidence. Darnbrough, Goddard and Stevely claim that such evidence tends to be put to one side to await future investigations which will either show the evidence to be erroneous or permit its asssimilation into the original theory. They neglect to point out that the development of creation theory through time, unlike evolutionary theory, has been one long retreat from the evidence. In order to assimilate anomalous evidence, numerous ad hoc changes have been made to creation theory. Such alterations were made in respect to the age of the Earth, the number of centres of creation, the number of separate creations and catastrophes through time, and the existence of variation within species, to name only the better known examples. Meanwhile, evolutionary theory has not been without its own troubles, as the current debate over possible rates of evolution shows. However, in the past, anomalies have been assimilated into evolutionary theory in a non ad hoc manner, leading to the further articulation and development of the theory. This is a major difference between the two theories.

What is being claimed here is that evolutionary theory is explanatory and has a heuristic function which helps our understanding of natural phenomena to grow. Creation theory, however, is a pseudoexplanation which aids us not at all in our understanding of nature and leads us nowhere. Naturally individuals may hold any metaphysical beliefs they wish, but the introduction of the notion of supernatural creation into scientific explanations should be resisted as contributing nothing, or worse, to our understanding of the world. 